\title{
INTERACTIONS OF POLYSACCHARIDE-COATED NANOPARTICLES WITH PROTEINS
}

\section{Christine VAUTHIER ${ }^{1,2}$}

1 Univ Paris-Sud, Faculté de Pharmacie, 5, rue J.B. Clément, 92296 Châtenay-Malabry Cedex, France

2 CNRS UMR 8612, Institut Galien Paris-Sud, 5, rue J.B. Clément, 92296 Châtenay-Malabry Cedex, France

Published in: "Biointeractions of Nanomaterials". Vijaykumar B. Sutariya and Yashwant Pathak, Editors. CRC Press, Taylor and Francis. Bocca Raton, FL. July 2014. Chap 18, pp. $365-382$ (2014) ISBN 13 :978-1-4665-8238-5. Available on: https://doi.org/10.1201/b17191.

\section{Corresponding author}

Christine Vauthier, Institut Galien Paris-Sud, University of Paris Sud, UMR CNRS 8612, Faculté de Pharmacie, 5 Rue J.B. Clément, F 92296 Châtenay-Malabry France

E-mail: Christine.vauthier@u-psud.fr, Phone 3314683 56 03/Fax 33146835946

\begin{abstract}
One of the challenges developing nanomedicines for drug delivery by the intravenous route is to control protein adsorption on nanoparticle surface that is parts of mechanisms behind recognition of carriers by the immune system hence controlling their in vivo fate. It is known that protein interactions with drug carriers can be modulated by modifying their surface properties. This book chapter reports the use of polysaccharides as alternative material to poly(ethylene glycol) (PEG) to control protein adsorption on nanomedicines. The first part presents the characteristics of a series of model nanoparticles obtained from the synthesis of polysaccharide-coated poly(alkylcyanoacrylate) nanoparticles. The second part presents our knowledge on the interactions of proteins with those nanoparticles. It is pointed out that the wide ranges of properties that can take polysaccharides can be used to tune surface properties of nanoparticles modulating qualitatively and quantitatively the type of proteins adsorbing on their surface. Interactions of proteins can be modulated according to several mechanisms including a steric exclusion effect or the promotion of a biological activity (case of heparin). It is also possible to control simultaneously the activation of the complement system which is beyond the recognition of the nanoparticles by the immune system and the adsorption of various types of proteins in a controlled manner. A lot of work is still needed to explore all potentials offered by the use of polysaccharides. Although challenging, their use designing corona stabilizing nanoparticles can open a new era in the development of nanomedicine. Types of proteins adsorbing on nanoparticle surface can potentially be selected from the wide panel of characteristics that can be given to nanoparticle corona using polysaccharides hence improving our means to control their in vivo biodistribution after intravenous injection.
\end{abstract}




\section{Summary}

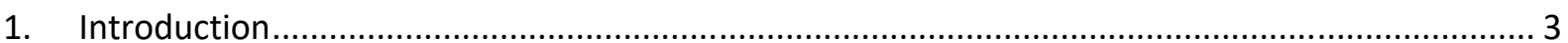

2. Synthetic identity of polysaccharide-coated poly(akylcyanoacrylate) nanoparticles.................6 6

3. Interactions of polysaccharide-coated nanoparticles with proteins................................... 11

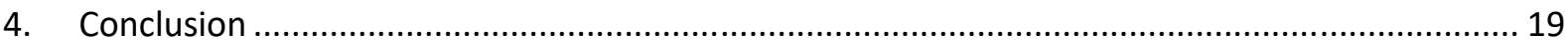

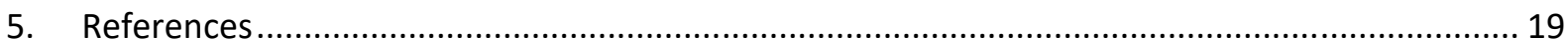

\section{Key words for the Index}

Activation of complement

Adsorption of protein

Biological identity

Complement system

Dextran

Immune system

nanomedicine

nanoparticle

Nanoparticle core

Nanoparticle corona

Nanoparticle surface

Polyelectrolyte

Poly(ethylene glycol)

Polysaccharide

Protein adsorption

Synthetic identity 
Author manuscript published in: "Biointeractions of Nanomaterials". Vijaykumar B. Sutariya and Yashwant Pathak, Editors. CRC Press, Taylor and Francis. Bocca Raton, FL. July 2014. Chap 18, pp. 365-382

\section{Introduction}

Nanomaterials occurring as single particles within the nanosize range are small enough to diffuse in living tissues of the organisms and to penetrate cells. Synthesis of artificial nanomaterials appeared enough reproducible at the end of the 1960's and beginning of the 1970's [Bangham et al., 1965, see for references Daniel J.C. 2003]. They appeared suitable to serve as drug carriers [Gregoriadis, 1976, Kreuter and Speiser, 1976, Kreuter, 2007] and attracted immediate interest to realize the "magic bullet", a concept imagined by Paul Ehrlich winner of the Nobel Prize in Physiology and Medicine in 1908. The rational behind this idea was to develop method of drug delivery reducing severe side effects of drugs used in chemotherapies of cancer and infections thanks to a better targeting of the drug to diseased tissues. Early stages of developments of nanomedicines have considered liposomal formulations of chemotherapeutic agents during the 1970's [Gregoriadis, 1976, Juliano, 1976, Gregoriadis et al, 1974]. Since then, the field of nanomedicine has considerably expanded. Many types of nanomaterials have been proposed to serve as drug carriers for small molecules but also for biomacromolecules including therapeutic peptides, proteins and all kinds of nucleic acids that can be used to control the expression of a specific gene and applied in gene therapy. Proofs of concept for the delivery of most of these molecules considering different modalities for their administration have now been provided [Couvreur and Vauthier 2006, Farokhzad and Langer 2009, Etheridge et al. 2013, Lehrner et al 2013]. Besides applications which overcome drug delivery challenges, several types of nanomaterials were found interested to improve performance of imaging techniques used in diagnostic [Liu et al. 2011]. The new nanomedicine field called theragnostic uses a combination of drug delivery and diagnostic in a single nanomaterial [Mura and Couvreur 2012]. Finally, several types of nanomaterials can be used to potentiate the effect of radiotherapy [Bakht et al. 2012]. They are used to focus effects of radiations after implantation within tumours which enhances the efficacy of the radiotherapy. Several of these nanomaterials are bringing the hope to develop non-invasive methods for tumour ablation with the ambition to displace classical surgery.

It is now established that many types of nanoparticles have the potential to revolution diagnostic and therapeutic methods [Wang et al. 2013, Lehner et al. 2013, Etheridge et al. 2013]. However, success is closely conditioned by their biodistribution while they are intended to be administered in vivo by a general route of administration, i.e. oral or intravenous. In turn, the expected biodistribution is closely conditioned on how nanoparticles interact with biological media especially those they found on their way between the site of administration and their target sites [Alexis et al. 2003, Owens and Peppas, 2006, Dobrovolskaia et al. 2008, Walczyk et al. 2010, Moyano and Rotello, 2011]. Considering administration of a nanomedicine by the intravenous route which is a typical route considered for their administration, immediate interactions include adsorption of proteins on the nanomaterial surface. A layer of proteins forms at the surface of the nanomedicine changing their "synthetic identity" into a "biological identity" [Lynch et al. 2007, Dobrovolskaia et al. 2008, Norde 2008, Walkey et al., 2012, Walkey and Chan 2012]. This event determines and regulates subsequent biological response that will control, in final, the in vivo fate of the nanomedicine including its eventual toxicity. Understanding interactions of nanomedicines with blood proteins is considered as a fundamental issue to predict and control their biodistribution and the eventual toxicological reaction they may induce [Lynch et al. 2007, Walkey and Chan 2012]. While this is expected to provide with a better understanding on how physico-chemical properties of nanomedicines which 
Author manuscript published in: "Biointeractions of Nanomaterials". Vijaykumar B. Sutariya and Yashwant Pathak, Editors. CRC Press, Taylor and Francis. Bocca Raton, FL. July 2014. Chap 18, pp. 365-382

define their "synthetic identity" influence the in vivo fate, it will enable a rational design of safe and efficient nanomedicines. Considering the broader range of applications offered by nanotechnologies that far exceed that of nanomedicines, elucidation of interactions occurring between nanomaterials and proteins is expected to contribute to evaluate and elucidate health and environmental risks which may arise from their use in various domains of the industry and in consumer products distributed on a large scale.

Investigating interactions of proteins with nanomaterials is a complex task. Nanomaterials occur with various composition, size, shape, and surface properties [Algar et al. 2011, Etheridge et al. 2013, Lehner et al. 2013]. A glance of this complexity is provided considering the nature of components composing nanomaterials developed as nanomedicines. These include lipids, polymers, carbon, and metal for the simpler. More complex systems are composites resulted from the association of metal colloids and lipids or polymers for instance. A second difficulty arises from the large number of proteins that are found in the blood and the broad range of concentrations they individually occur. There is above 1000 different proteins with differences in concentrations spread over 10 orders of magnitude [Anderson et al. 2004]. Additionally, the adsorption of protein on a surface of a material is kinetically dependant and the composition of the adsorbed proteins evolves with time [Hirsh et al. 2013]. Finally, investigating interactions of proteins with nanomaterials is not simply an extension of approaches applied on biomaterials. The range of size of nanomaterials imposed the development of specific methods. Some were adapted from those used to evaluate biomaterials, but a lot needed to be developed specifically to be applied on nanomaterials [Lynch et al. 2007, Vauthier et al. 2009, 2011, Walkey and Chan 2012, Welsh et al. 2013].

Research carried on interactions of proteins with nanoparticles were intensified over the last twenty years. They have started soon after it was assumed that proteins play a fundamental role defining the in vivo fate of nanomaterials including those designed as drug carriers. Today, it is expected that the biodistribution of nanomaterials may be anticipated from the type of proteins that adsorbed on their surface. It is also assumed that it may be possible to target a nanomaterial to a specific site in the organism taking advantage of a preferential adsorption of a certain plasma protein if it exists and to the specific design of the nanomaterial. While taking advantage of the preferential adsorption of protein may be a strategy to conceive targeted nanoparticles for drug delivery, a systematic identification of proteins that adsorb on nanomaterials could be used as a method identifying preferential sites of accumulation in the body in the purpose to anticipate the safety of a nanomaterial. In parallel to research carried out to decrypt the type of proteins adsorbing on nanoparticle surface, methods of camouflaging the surface of nanoparticles were developed. To this purpose, poly(ethylene glycol) (PEG) was chosen because of its known antifouling properties thanks from its uses to improve resistance to protein adsorption of biomaterials [Jeon and Andrade 1991, Jeon et al. 1991, Gref et al. 1994, Paphadjopooulos et al. 1991, Banerjee et al. 2011]. Together with observations of the occurrence of modifications of protein adsorption, the addition of PEG at the surface of nanomaterials could modulate the pharmacokinetic and biodistribution of the corresponding nanoparticles [Gref et al. 1997, Gref et al., 2000, Perracchia et al. 1999, Vonabourg et al. 2006, see for review Li and Huang 2008]. However, the use of PEG presents some limitations following observations from the clinics while the use of PEGylated nanomedicines was intensified in human medicine. The most serious concerns the appearance of a new type of toxicity which occurs as a hypersensitive reaction called C activation-related pseudoallergy (CARPA) [Jiskoot et al., 2009, Szebeni et al. 2011, Lehner et al. 2013]. Only few works have considered the use of alternative 
Author manuscript published in: "Biointeractions of Nanomaterials". Vijaykumar B. Sutariya and Yashwant Pathak, Editors. CRC Press, Taylor and Francis. Bocca Raton, FL. July 2014. Chap 18, pp. 365-382

polymers to PEG to modulate surface properties of nanoparticles in the aim to modify protein adsorption. The few numbers of polymers used in this purpose included polyoxazolines, oligo and polysaccharides, polyelectrolytes and zwitterionic polymers [Passirani et al. 1999, Chauvierre et al., 2003, Labarre et al., 2005, Lemarchand et al. Estephan et al., 2010, Walkey and Chang 2012, Welsch et al. 2013]. Whatever the approach used to modify surface properties of nanoparticles, the control of the in vivo fate of a nanomedicine from the protein adsorption pattern needs the understanding of the relation between the synthetic identity of the nanomaterials, its biological identity and the corresponding physiological response. Each can be described by many parameters that considerably increase the challenge. We should admit that we are still at the beginning of the works. Nevertheless, a few general principles have emerged from the number of studies available in the literature. For instance, Walkey and Chan [2012] have provided a comprehensive analysis of data collected from many of these works. They described an "adsorbome" of 125 plasma proteins for nanoparticles of various compositions and surface properties. From this analysis, they draw a relation between the physico-chemical characteristics of the nanoparticles and the corresponding absorbome. The difficulty of this work came from the various sources of data hence the wide range of nanoparticles. Unfortunately, this analysis could obviously not be based on standardized evaluations of nanomaterial properties and of protein adsorption. In agreement with the finding of the authors, this would be the main restriction of this work. Nevertheless, such an analysis deserves of respect and will be very useful in the future. The conclusion which came out of this work was that 2 to 6 proteins from plasma predominantly adsorbed on the surface of a nanomaterials together with many more that adsorbed at a lower abundance. Another remarkable analysis was provided by Walkey et al. [2012] considering a series of PEGylated gold nanoparticles and investigating in parallel their "absorbome" and their uptake by macrophages. It also emerged from all the work done that polyethylene glycol chains grafted at the surface of nanoparticles control the adsorption of proteins by a steric effect [Gref et al. 2000, Walkey et al. 2011, for other ref see Owens and Peppas, 2006, Alexis et al., 2008]. The use of polyelectrolytes as coating materials of nanoparticles leads to a different mechanism of control of the adsorption of proteins on the nanoparticle surface. In this case, proteins were found to behave like multi-counterions that can interact with the charge of the polyelectrolytes via the patches of opposite charges they display on their surface [Ballauff and Borisov, 2006, Ballauff, 2007, Welsch et al. 2013]. In our group, we have started investigating interactions of proteins with polysaccharide coated poly(alkylcyanoacrylate) (PACA) nanoparticles. These nanoparticles have the potential to improve the delivery of many types of drugs [Vauthier et al. 2007, Andrieux et al. 2009, Julien and Couvreur, 2009]. They can be obtained with various surface properties thanks to their method of preparation and the large panel of polysaccharides that can be used as coating materials [Julien and Vauthier 2011]. The aim of this chapter was to propose a comprehensive review of our contribution to the understanding of the influences of nanoparticle properties on interactions with blood proteins. In the first part, we summarize the characteristics of a series of polysaccharide coated PACA nanoparticles that were synthesized to carry on our work. Results on the interactions of proteins with nanoparticles are presented in the second part of the chapter. As it will be explained, models drawn to describe the "synthetic identity" of several nanoparticles could be used to elucidate mechanisms controlling the accessibility of proteins to the nanoparticle surface during protein adsorption. It also served to understand mechanisms beyond the capacity of the nanoparticles to trigger activation of proteins involved in the immune system which play a fundamental role to define the in vivo fate intravenously injected nanoparticles. 


\section{Synthetic identity of polysaccharide-coated poly(akylcyanoacrylate) nanoparticles}

PACA nanoparticles are developed as drug carriers for various purposes since 1979. Their design has evolved with time to adjust their properties with that required to fulfil the different drug delivery strategies to achieve. These included functions required to associate various types of drugs and functionalities needed to adjust their in vivo biodistribution after intravenous injection. It leads to various types of PACA nanoparticles which were all spherical in shape but differed from their size, composition, and surface characteristics (Table 1).

Table 1: Conditions of fabrication of a series of model nanoparticles coated with dextran as polysaccharides and corresponding models deduced from the characteristics of the copolymers that composed them

\begin{tabular}{|c|c|c|c|c|}
\hline Name & $\begin{array}{l}\text { Method of } \\
\text { polymerization }\end{array}$ & $\begin{array}{l}\text { Conditions of } \\
\text { polymerization }\end{array}$ & $\begin{array}{l}\text { Structure of the } \\
\text { copolymer } \\
\text { PIBCA/Dextran }\end{array}$ & $\begin{array}{l}\text { Model proposed for the } \\
\text { nanoparticles }\end{array}$ \\
\hline $\mathrm{A} 1$ & $\begin{array}{l}\text { Anionic } \\
\text { polymerization }\end{array}$ & $\begin{array}{l}\text { pH } 1 \\
\text { dextran 70KD } 1.3 \%\end{array}$ & & $\begin{array}{c}\text { lonse } \\
\text { loops } \\
\mathrm{D}_{\mathrm{H}}: 86 \mathrm{~nm}, \zeta=-8.7 \mathrm{mV}\end{array}$ \\
\hline$A 2$ & $\begin{array}{l}\text { Anionic } \\
\text { polymerization }\end{array}$ & $\begin{array}{l}\text { pH } 2.5 \\
\text { dextran 70KD } 1.3 \%\end{array}$ & & $\begin{array}{c}\text { tight } \\
\text { loops } \\
\mathrm{D}_{\mathrm{H}}: 181 \mathrm{~nm}, \zeta=-1.1 \mathrm{mV}\end{array}$ \\
\hline $\mathrm{R} 1$ & $\begin{array}{l}\text { Radical } \\
\text { polymerization }\end{array}$ & $\begin{array}{l}\text { pH } 1 \\
\text { dextran 70KD } 1.3 \%\end{array}$ & 1 & Dн: $224 \mathrm{~nm}, \zeta=-11.6 \mathrm{mV}$ \\
\hline $\mathrm{R} 2$ & $\begin{array}{l}\text { Radical } \\
\text { polymerization }\end{array}$ & $\begin{array}{l}\mathrm{pH} 1 \\
\text { dextran 70KD } 0.5 \%\end{array}$ & & $\mathrm{D}_{\mathrm{H}}: 180 \mathrm{~nm}$ \\
\hline R3 & $\begin{array}{l}\text { Radical } \\
\text { polymerization }\end{array}$ & $\begin{array}{l}\text { pH } 1 \\
\text { dextran 15KD } 1.3 \%\end{array}$ & & $\begin{array}{c}\text { short } \\
\mathrm{D}_{\mathrm{H}}: 200 \mathrm{~nm}, \zeta=-19 \mathrm{mV}\end{array}$ \\
\hline
\end{tabular}


In general, size of polysaccharide-coated PACA nanoparticles ranged between a few tens of nanometers (45-50 $\mathrm{nm}$ in diameter for the smaller) and several hundreds of nanometers (350 - 400 $\mathrm{nm}$ in diameter for the larger). PACA nanoparticles are composed of copolymers including at least one segment of PACA and one segment of a hydrophilic macromolecule [Douglas et al. 1984, Chauvierre et al. 2003, Bertholon et al., 2006a, Zandanel et al., 2012]. As depicted in table 1, the copolymers take different structures depending on the conditions used for their synthesis. Thanks to the amphiphilic properties of the copolymers, nanoparticles produced in an aqueous medium occur as stable dispersions and take a core-corona structure. The hydrophobic segments of the copolymers precipitate to compose the core of the nanoparticles while the hydrophilic part is exposed at the nanoparticle surface (Figure 1).

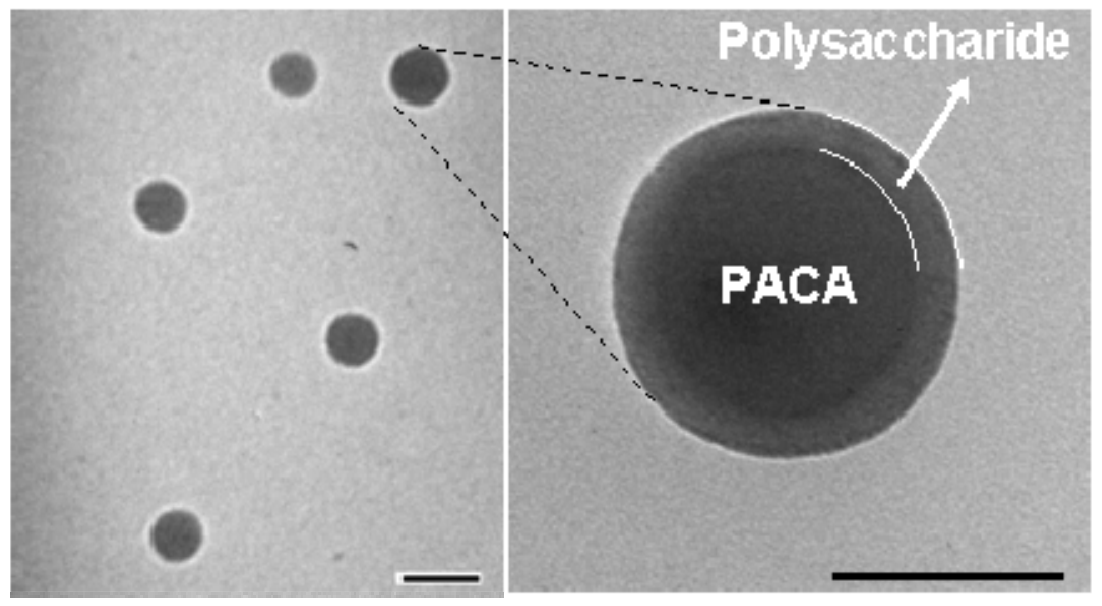

Figure 1: Electron micrograph of polysaccharide coated PACA nanoparticles. The nanoparticles were prepared by radical polymerization of isobutylcyanoacrylate carried out with chitosan 20KD. The nanoparticles were composed of a core of PIBCA, and a corona of chitosan as depicted on the right image. The nanoparticles deposited on a formvar-carbon coated cupper grid for electron microscopy were stained with phosphotungstic acid for $30 \mathrm{~s}$. Scale bar = $100 \mathrm{~nm}$. Cliché: H. De Martimprey. Service commun de Microscopie électronique, Orsay, France.

This core-corona structure forms thanks to the thermodynamics of the system in the course of nanoparticle synthesis which evolve to obtain the more stable aqueous dispersions of nanoparticles. A primary indication of the nature of the component included in the nanoparticle corona can be given by measuring the zeta potential of the nanoparticles. In general, the zeta potential shown by the nanoparticles is consistent with the value expected considering the nature of the macromolecule (i.e., the polysaccharide) composing the hydrophilic part of the copolymer. The Figure 2 gives examples of zeta potential of PACA nanoparticles composed of copolymers including various types of polysaccharides.

Some of the nanoparticles included in the Figure 2 were prepared with blends of polysaccharides and blends of polysaccharide and pluronic ${ }^{\circledR} 68$. It is noteworthy that such nanoparticles display intermediate properties compared with those of nanoparticles obtained with each hydrophilic macromolecule taken separately indicating that they formed by the assembling of the different copolymers produced during polymerization. 


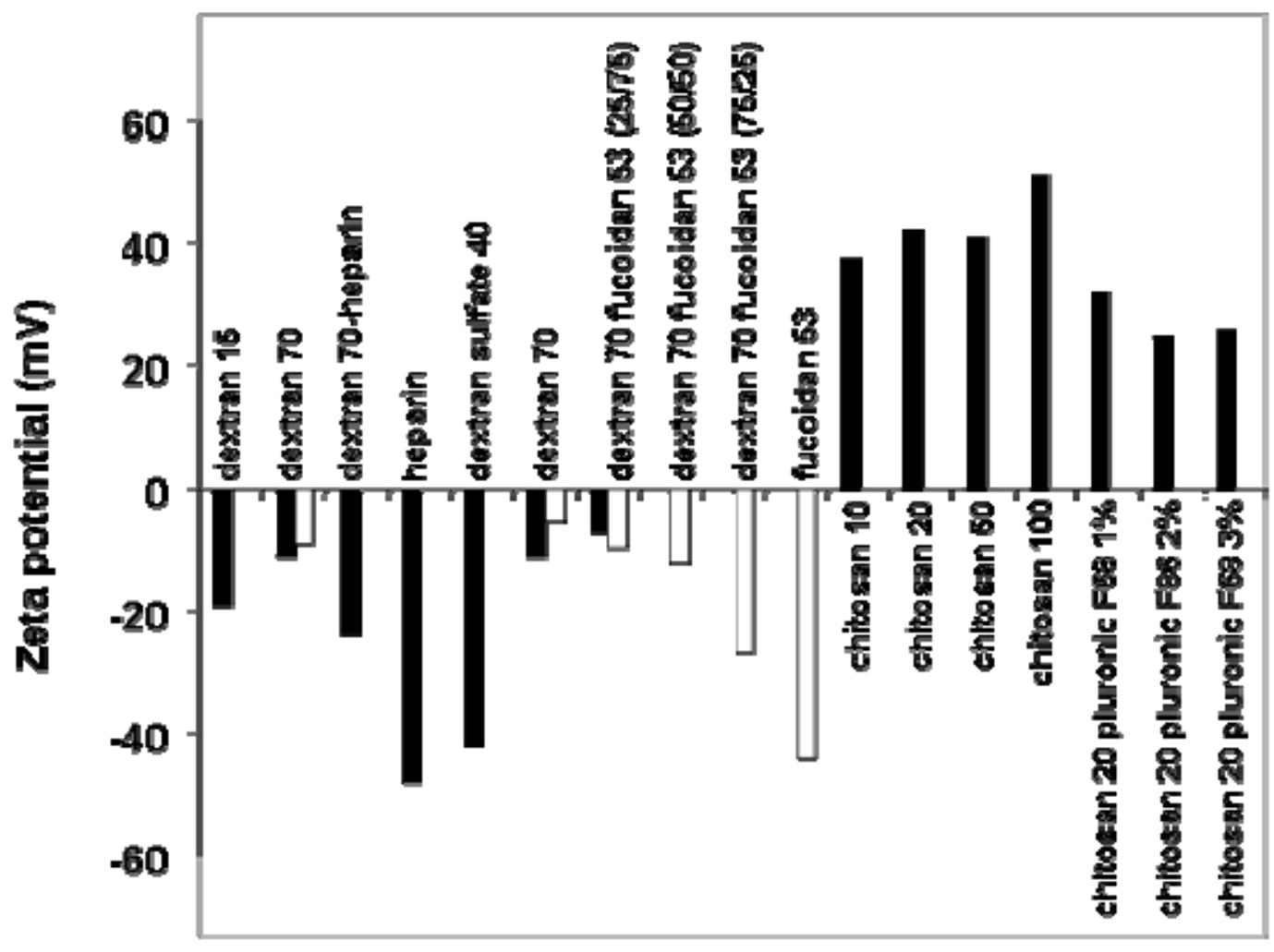

Nature of the polysaccharides

Figure 2. Zeta potential of nanoparticles produced with different polysaccharides [Lira et al. 2011, Bravo et al. 2007, De martimprey et al., 2009, Labarre et al., 2005]. Numbers following the name of the polysaccharide indicates the molecular weight in KDa. White columns: nanoparticles obtained by anionic polymerization. Black columns: nanoparticles obtained by radical polymerization.

Determination of the "synthetic identity" of nanoparticles in the aim to understand their interaction with proteins requires deeper description of their characteristics especially of the structure of their corona. Such efforts were carried out on PEG-coated nanoparticles and nanoparticles coated with brushes of polyelectrolytes [Gref et al. 2000, Welsch et al. 2013]. Models of the organization of the chains of PEG or polyelectrolytes could be suggested providing with a clear understanding of the structure of the nanoparticle surfaces. In our work, we have characterized a series of polysaccharide coated PACA nanoparticles to provide with a comprehensive view of the structure of the nanoparticle corona [Bertholon et al. 2006b, Vauthier et al. 2009, 2011, Zandanel and Vauthier, 2012]. In contrast with polymers composing PEGylated nanoparticles, polymers composing polysaccharide coated PACA nanoparticles are synthesized at the time of the preparation of nanoparticles by emulsion polymerization. This implies that the structure of copolymers composing the nanoparticles needs to be characterized from the obtained nanoparticles. As in the case of many amphiphilic copolymers, the polysaccharide-PACA copolymers composing the nanoparticles were difficult to characterize. The main difficulty rose from the fact that they were not soluble in solvents commonly used for polymer analysis. The only solvent in which the copolymers forming the nanoparticles could apparently dissolve was DMSO. However, the obtaining of a true solution in which polymer molecules occur as single and well individualized chains could only be obtained at a low concentration. Above a concentration of $1.1 \mathrm{mg} / \mathrm{mL}$, the copolymer molecules aggregated together forming larger objects that could correspond to micelles [Bertholon et al. 2006b]. True solutions of copolymers occurred at lower concentration than that required to perform analysis with 
usual methods applied to characterize polymers form solutions. To turn around this analytical problem, methods of selective degradation of the two types of polymers included in the copolymer

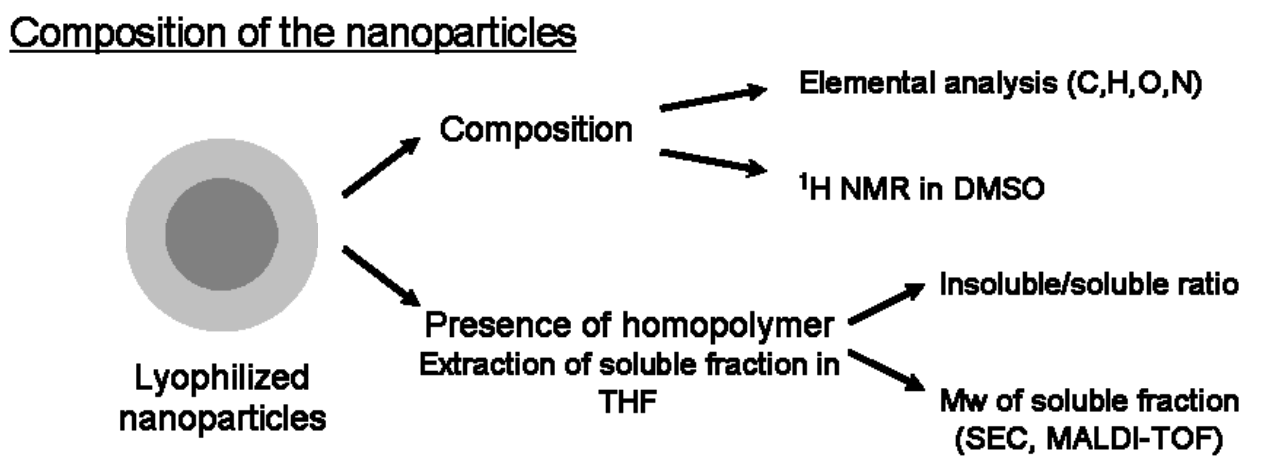

\section{Composition and structure of the copolymer}

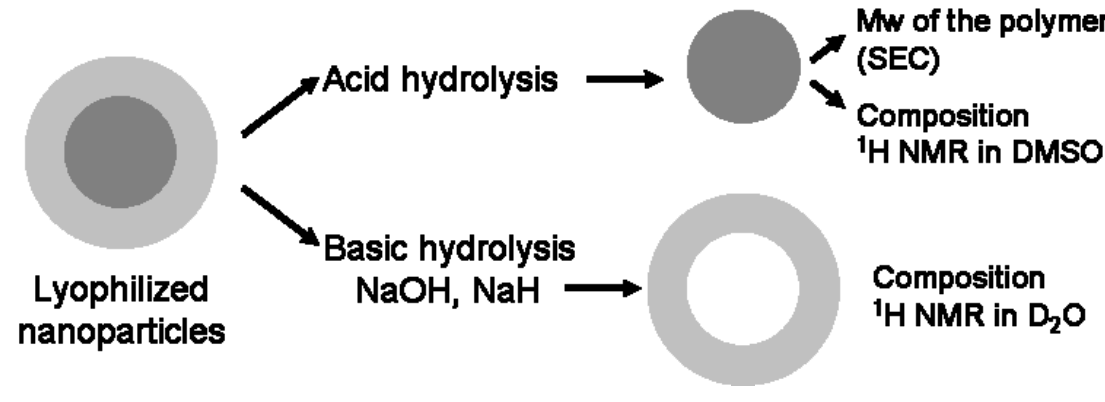

Figure 3: Scheme explaining the strategy developed to analyse the composition and the structure of copolymers composing polysaccharide coated PACA nanoparticles.

After purification, the polymer chains which were not degraded by the selective treatment of either the PACA chains or the polysaccharide segments could be characterized as a homopolymer. This methodology is time consuming and needs lots of efforts validating all steps. The selectivity of the degradation methods needed to be demonstrated. It was shown that conditions of degradation applied to remove PACA did not modify the characteristics of the polysaccharide and vice versa. Nevertheless, this complex procedure provided with structure of copolymers composing polysaccharide coated PACA nanoparticles obtained in different conditions of synthesis. Depending on their structures, the copolymers can be classified in two categories which depended on the type of polymerization applied to synthesize the nanoparticles. They occurred as linear block copolymers when the nanoparticles were prepared by radical polymerization and as comb copolymers when the synthesis of the nanoparticles occurred by anionic polymerization (Table 1) [Bertholon et al., 2006b, Zandanel and Vauthier, 2012].

This difference in the structure of the copolymer generates a fundamental difference on the characteristics of the nanoparticle corona considering that the polysaccharide part of the copolymer is anchored in the core of the nanoparticles thanks to the contribution of the PACA segments. Consequently, the number of PACA segments attached on the polysaccharide determines its spatial arrangement in the nanoparticle corona and its freedom to move (Table 1) (Chauvierre et al. 2004, Bertholon et al., 2006c). Simulations of the structure of the corona of a few polysaccharide coated PACA nanoparticles could be suggested. Models showing the configuration of polysaccharide chains 
in nanoparticle corona could be drawn from the structure of the copolymers [Bertholon et al. 2006b, Zandanel et al., 2012]. Improved simulations were carried out from the composition in polysaccharide and PACA of the copolymer, the structure of the copolymer, the diameter of the core of the nanoparticles and their hydrodynamic diameter. Models drawn from the improved simulations can provide with information about the density of the polysaccharide chains within the nanoparticle corona [Vauthier et al. 2009, 2011]. The table 2 summarizes the models established from the deep characterization of several PACA nanoparticles coated with dextran which were then used to investigate their interactions with proteins.

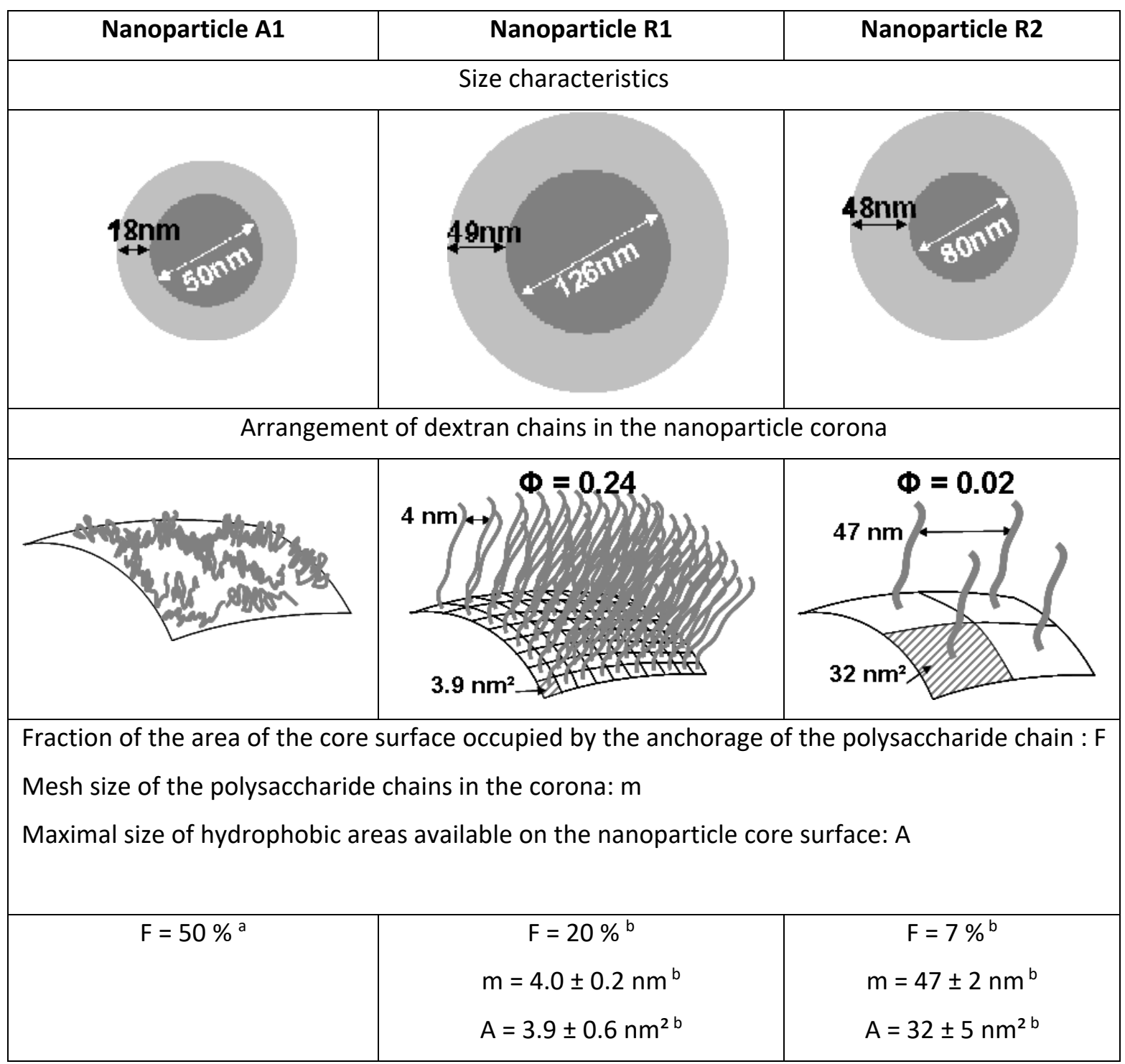

Table 2: Fine description of the synthetic identity of the dextran-coated nanoparticles prepared in different conditions (see table 1 for conditions of preparation). $\Phi$ gives the volume fraction occupied by dextran chains in the nanoparticle corona. ( ${ }^{a}$ Vauthier et al., 2009, ${ }^{b}$ Vauthier et al., 2011) 
Author manuscript published in: "Biointeractions of Nanomaterials". Vijaykumar B. Sutariya and Yashwant Pathak, Editors. CRC Press, Taylor and Francis. Bocca Raton, FL. July 2014. Chap 18, pp. 365-382

\section{Interactions of polysaccharide-coated nanoparticles with proteins}

When nanoparticles, or more generally drug carrier nanotechnologies, are injected in the blood, proteins immediately interact with the foreign particles. A first interaction consists on adsorption or deposition of proteins on the material surface. During this event, the surface of particles is decorated with blood proteins. The layer of proteins which forms gives a "biological identity" to the nanoparticles that play a fundamental role on subsequent events [Vonabourg et al. 2006, Nilsson et al. 2007, Alexis et al. 2008, Dobrovolskaia et al. 2008]. For instance, the access of the nanoparticle surface to certain proteins can trigger activation of the immune systems. When the immune system is activated, the particle is rapidly taken up by macrophages in charge of the elimination of foreign bodies. This strategy may be used to target drugs to the immune system, but it hampers the delivery of drugs to other organs and tissues. The approach used to escape the capture of drug carriers by macrophages is to mask the nanoparticle surface with hydrophilic polymers to modify the composition and amount of the adsorbed layer of proteins which forms when nanoparticles are injected in the blood. The grafting of polyethylene glycol chains was a very efficient strategy to hamper adsorption of proteins on the surface of nanomaterials used as drug carriers [Gref et al. 2000, Owens and Peppas, 2006, Vonabourg et al. 2006, Alexis et al. 2008, Li and Huang, 2008]. It continues to be actively studied as the understanding on how particle design influences protein adsorption remains incomplete [Walkley et al., 2012, Walkey and Chang, 2012]. Besides these works, we have started investigating interactions of proteins with the model nanoparticles of PACA coated with polysaccharides for which we could described the synthetic identity of the hydrophilic corona. Our studies aimed to answer several questions:

- Where proteins adsorbed on nanoparticle surface assuming that they may remain on the top of the hydrophilic corona, they may be entrapped within the hydrophilic corona or they may adsorb on the surface of the hydrophobic core?

- What are the parameters regulating protein adsorption assuming that the synthetic identity of the nanoparticle corona may greatly interfere in this process?

- What are the properties of the polysaccharide corona behind activating or non-activating proteins of the immune system?

Answering the first question was an issue to estimate the role of the nanoparticle corona in controlling interactions between nanoparticles and proteins. Obviously, this role was expected to differ greatly whether the proteins remained on the top of the corona surface or penetrated through this layer to either remained retained in the corona (Figure $4 A, B$ ) or diffused across to reach the hydrophobic core of the nanoparticles (Figure 4C).

Results from a series of experiments designed to highlight protein depot on the surface of dextran coated PIBCA nanoparticles led to the conclusion that proteins adsorbed on the hydrophobic core of the nanoparticles (Figure 4C) [Vauthier et al., 2009]. The obvious consequence drawn from this observation was that properties of the corona are fundamental to control accessibility of proteins to the nanoparticle core surface hence to control the whole phenomenon of protein deposition. Due to the anchorage of the dextran chains on the nanoparticle core surface, the space available to accommodate proteins adsorbing on the nanoparticle core is also function of the characteristics of the corona. Using a rather small protein, the bovine serum albumin (BSA), it could be shown that the access of proteins on the surface of nanoparticle core greatly depended on both the density of chains of dextran in the nanoparticle corona and their conformation. Results of experiments performed 
with other proteins suggested that it also greatly depended on the molecular weight, shape and dimensions of the proteins. A dense brush of chains of dextran leaves spaces for protein adsorption on the core surface of nanoparticles of much smaller size then a loose brush. However, the maximum amount of BSA that can be accommodated on the nanoparticle core surface is almost equivalent (2.1 $\pm 0.4 \mathrm{mg} / \mathrm{m}^{2}$ for nanoparticles R1 and $2.7 \pm 0.2 \mathrm{mg} / \mathrm{m}^{2}$ for nanoparticles R2) (Vauthier et al., 2011).

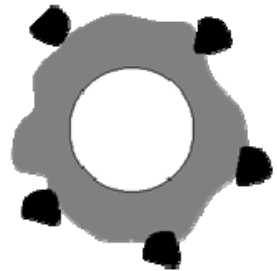

A

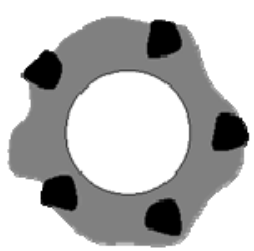

B

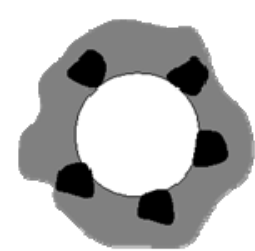

C

Figure 4:Scheme illustrating the different hypothesis drawn for protein adsorption on the nanopartides. The partide is illustrated with a white core and a grey corona while the proteins are shown by the blackspots. Adsorption of proteins taking place at the surface of the corona (A), within the polysaccharide corona (B) oron the surface of the hydrophobiccoreassuming that the proteins can diffuse across the polysaccharide corona (C). According to the experiments, proteins adsorbed on the surface of the hydrophobic core of dextran coated PIBCA nanopartides(hypothesis C)(Vauthier et al. 2009). Considering nanopartides coated with dextran sulphateor heparin, protein interactions may occur according to hypothesis $A$ and/or B.

This was explained by the rather small size of BSA. Comparing nanoparticles R1 and A1, the brush conformation of the chains of dextran in the corona of nanopartides R1 allowed a lower amount of BSA to adsorb on the nanopartide core then the loop conformation found on the surface of nanoparticles $A 1$ (maximum amount of BSA adsorbed at the surface of nanopartides $A 1=3.2$ $\mathrm{mg} / \mathrm{m}^{2}$ ) (Vauthier et al., 2009). An important other observation drawn from the experiment was that, only proteins which size suits with that of the free spaces can adsorb on the surface of the hydrophobic core. This is shown on figure 5 nanopartides with a dense brush of dextran (nanopartides R1) adsorbed a majority of low molecular weight proteins while the other nanoparticles (nanopartides A1, A2, R2) adsorbed larger amounts of immunoglobulin and fibrinogen which are proteins with high molecular weights.

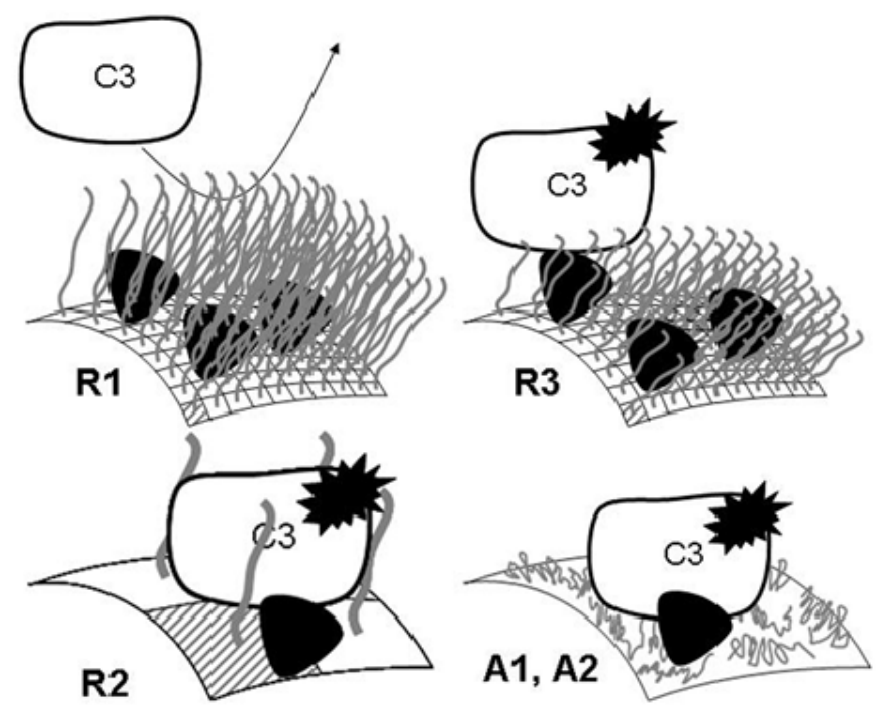

Figure 5:A schemeillustrating the interactions of proteins with a series of nanopartides having a corona of dextran with different characteristics. The dark spot induded in C3 indicates that the complement C3 of the complementsystem is activated. Albumin adsorbed on the surface of the nanopartide core appears as a dark triangle. 
The type of protein that adsorbed on the nanoparticle surface can be selected modulating both the conformation of the chains of dextran at the nanoparticle surface and the grafting density. A triage between proteins of low and high molecular weight applied at two levels. As explained above, the type of proteins that can adsorb on the nanoparticle surface depends on their size and on that of the hydrophobic areas available on the nanoparticle core. It also depends on the characteristics of the corona which function as a molecular sieve while proteins are diffusing across. Proteins which size and geometry does not allow them to diffuse through the mesh size of the polysaccharide layer that forms the corona are excluded and are not be able to reach the surface of the hydrophobic core of the nanoparticles (Figure 6).
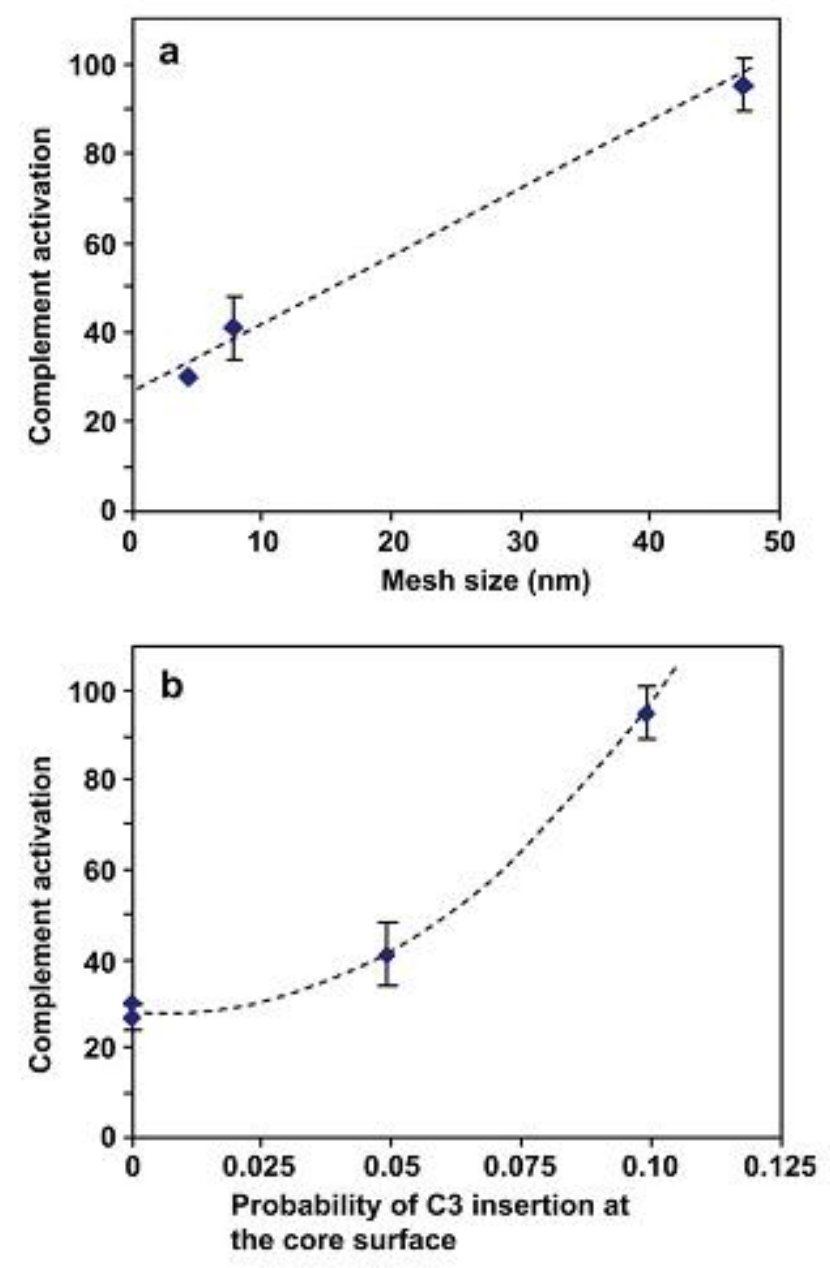

Figure 6: Relation between complement activation induced by the nanoparticles and the mesh size of the corona (a) and the insertion probability of the C3 protein at the core surface (b). [Reproduced from Vauthier et al. 2011, Biomaterials. 32:1646-56. with permission].

As it was found with PEG-coated nanomaterials, the density of the chain of dextran stranded on the surface of nanoparticles, their molecular weight and their conformation are factors that contribute to select the type and amount of proteins that adsorb on the nanoparticle surface. These factors also control the activation of the protein $\mathrm{C} 3$ of the complement system which play a central role in the activation of the complement cascade being part of the immune system [Nilsson et al., 2007]. A clear correlation was highlighted between the level of activation produced by the nanoparticles and the mesh size characteristics of the polysaccharide brush composing their corona (Figure 7A). 

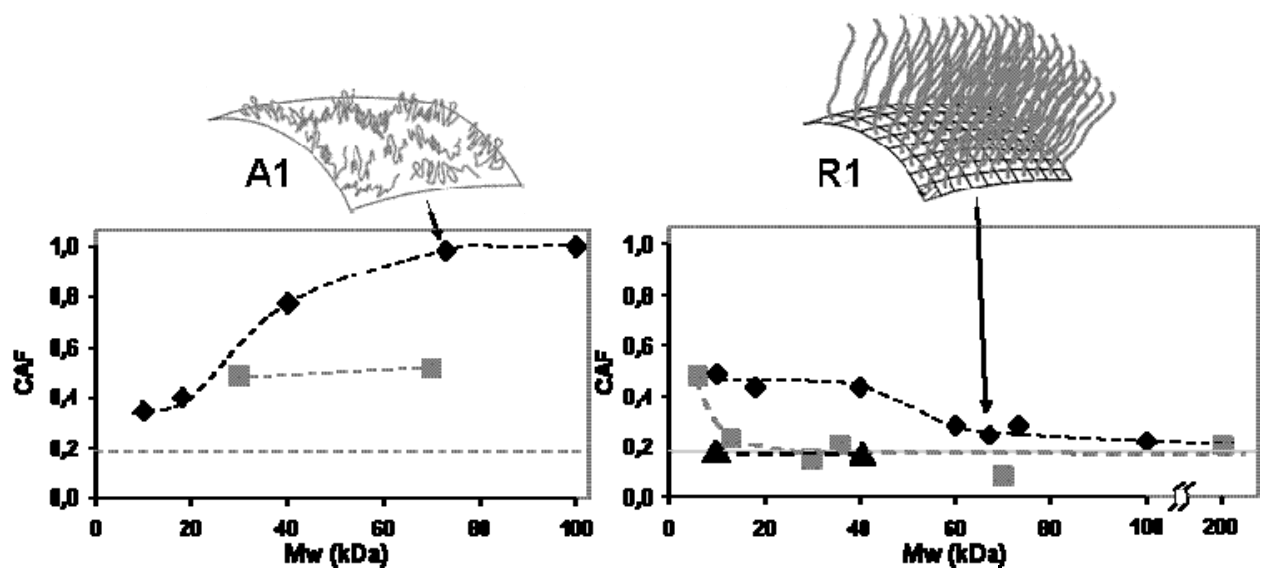

Figure 7: Complement activation factors (CAF) evaluated for nanoparticles prepared by anionic (left panel) and radical polymerization (right panel) with different polysaccharides (black diamond: dextran, grey squares: chitosan, black triangle: dextran sulphate) and varying their molecular weight. The basic activation of the complement system in the experimental conditions is indicated by the horizontal dotted line at a CAF of 0.195. On the top of the graphs, schemes illustrate the configuration of the polysaccharide chains in the corona of the nanoparticles according to the mechanism of polymerization applied to prepare the nanoparticles (CAF values were taken from Bertholon et al., 2006a, Model of the nanoparticle surface Vauthier et al., 2009, 2011 reproduced with permission)

Considering this correlation, it clearly appeared that the steric exclusion of the protein $\mathrm{C} 3$ from the nanoparticle corona can prevent activation of the complement system. The correlation between the probability of insertion of the protein $\mathrm{C} 3$ in the corona of dextran and the level of activation measured was not as good (Figure 7B). This was interpreted by the fact that activation of the protein C3 may be triggered by a layer of already adsorbed proteins which have changed conformation during adsorption on the nanoparticle core surface and that may be accessible to the C3 protein from the external part of the nanoparticles.

As discussed above, the density, the conformation and concentration of dextran chains in nanoparticle corona are factors controlling protein adsorption and complement activation. Activation of the protein $\mathrm{C} 3$ of the complement system was also controlled by the molecular weight of the dextran chains in the brush (Figure 8). Nanoparticles that activated protein C3 of the complement system had a brush of dextran chains with a molecular weight lower then $60 \mathrm{kDa}$. With a brush formed by dextran of higher molecular weight, the nanoparticles hampered the activation of protein C3 which is mandatory to escape the immune system in the vascular compartment. This result was not expected from the other characteristics of the nanoparticle corona because $\mathrm{C} 3$ was believed to be too large to diffuse through the dextran corona and to reach the surface of the core of the nanoparticle to be activated. As illustrated on the figure 6 for nanoparticle R3, the activation of C3 could be triggered by a layer of adsorbed proteins protruding out of the corona when the chains of dextran are too short to hide them. On the contrary, when the dextran chains are long enough (at least $60 \mathrm{kDa}$ ), the layer of adsorbed proteins can be masked in an efficient way. The fact that the protein $\mathrm{C} 3$ is excluded from the brush of dextran and that the adsorbed proteins are masked by the brush of dextran appeared as required factors to hinder the activation of the protein $\mathrm{C} 3$ of the complement system considering dextran-coated nanoparticles. 


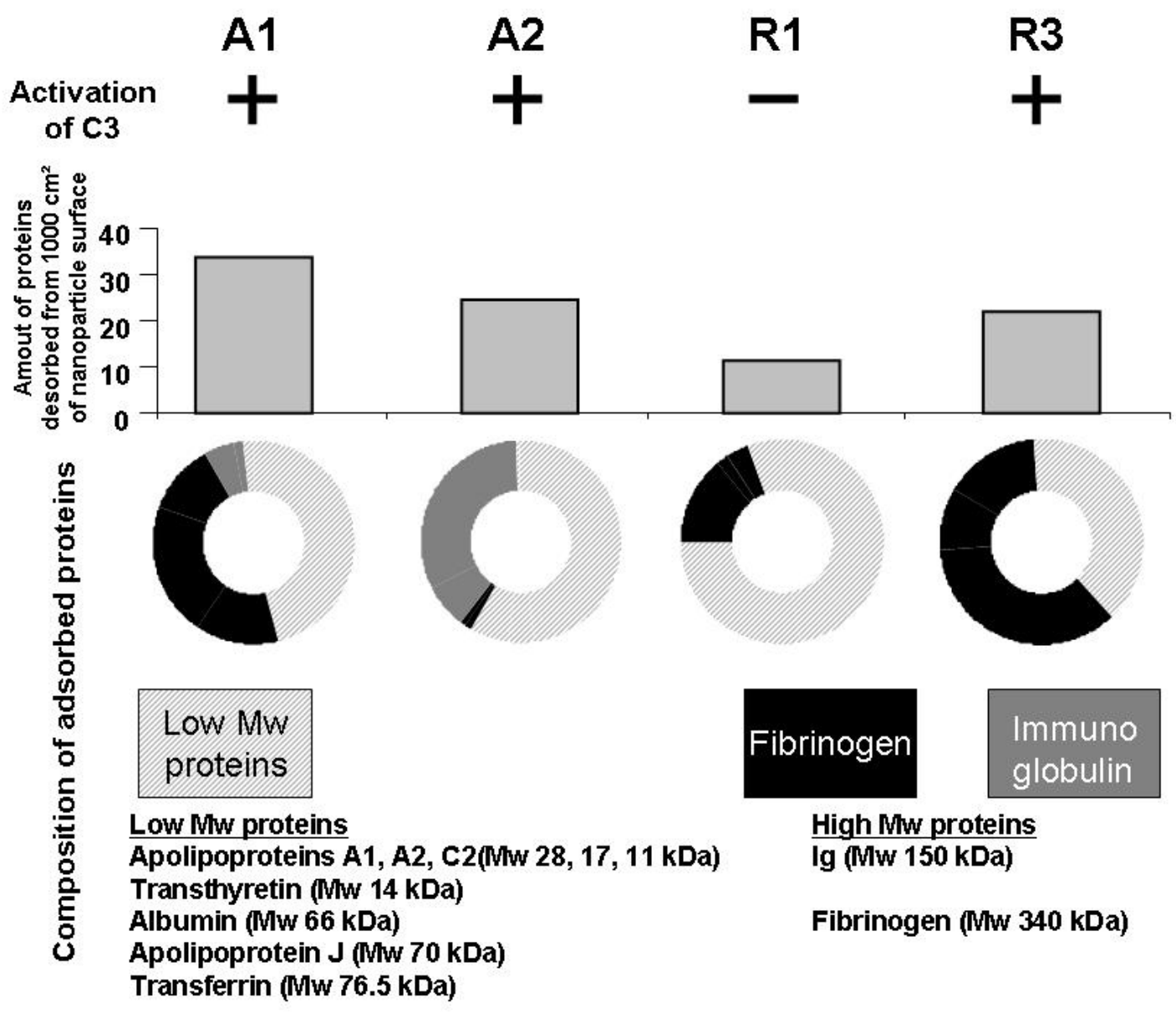

Figure 8: Protein adsorption on different dextran-coated nanoparticles and corresponding status of the activation of protein $\mathrm{C} 3$ of the complement system. The circles at the bottom represent the balance between proteins of high molecular weight (>100 kDa) (dark grey and black) and low molecular weight ( $<100 \mathrm{kDa}$ ) (light grey) that were found adsorbed at the nanoparticle surface after incubation in plasma. For proteins of high molecular weight a difference was made between fibrinogen (in black) and immunoglobulin (in dark grey).

A few conclusions can be drawn from the work done on dextran coated PACA nanoparticles. While proteins adsorbed on the hydrophobic core of the nanoparticles, the characteristics of the corona made of dextran control the type of proteins that can adsorbed and subsequent events including the activation of the complement system. A dense and thick brush of dextran is needed to hinder the activation of the complement system. Besides activation of the complement system, the composition of the adsorbed proteins can be modulated by varying the structure and characteristics of the corona. It is noteworthy that small changes can greatly influence the composition of the adsorbed proteins as illustrated by the comparison of protein adsorbed on nanoparticles A1 and A2 (Figure 5). All the results obtained from the analysis of protein interactions with our nanoparticles coated with chains of dextran suggested that the control of the adsorption of protein is achieved by a similar mechanism then that described with PEG nanoparticles being mainly governed by a steric effect.

In contrast with dextran-coated nanoparticles, the nanoparticles coated with charged polysaccharides behaved very differently. Nanoparticles having brushes of chitosan, heparin and dextran-sulfate prevented well the activation of the protein $\mathrm{C} 3$ of the complement system even at a 
low molecular weight. This effect was expected by designing nanoparticles coated with heparin which is an inhibitor of the activation of the complement system thanks to an interference with the factor $\mathrm{H}$ of the complement cascade [Nilsson et al., 2007]. Interestingly, the inhibiting property of heparin was maintained in nanoparticles designed with a brush composed of a blend of dextran and heparin. Further analyses were pursued on the nanoparticles coated with dextran sulphate, with heparin and with a blend of heparin and dextran. The analysis of the proteins that adsorbed on these nanoparticles revealed a majority of high molecular weight proteins including fibrinogen and immunoglobulin (Figure 9) [Labarre et al., 2007].

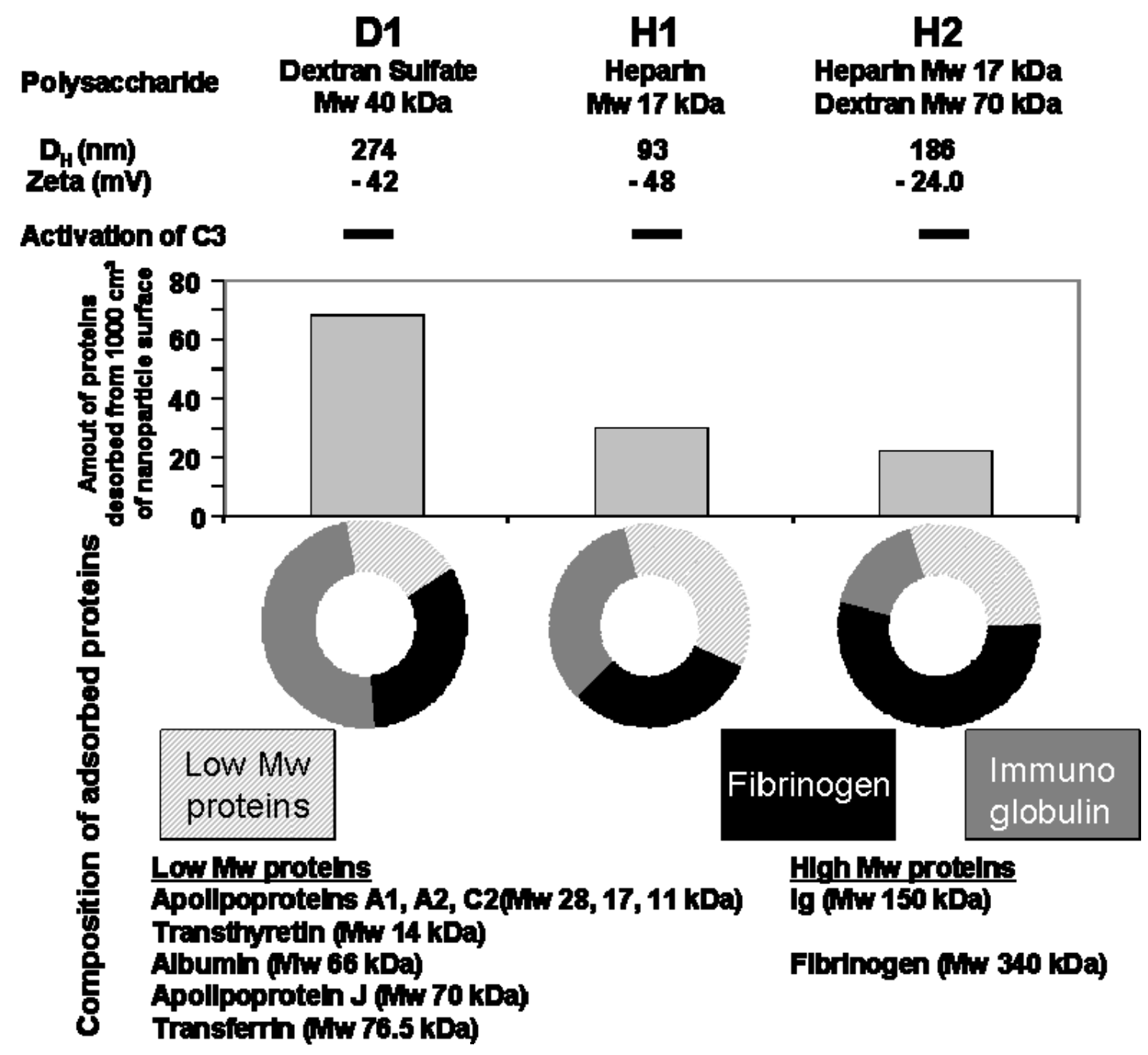

Figure 9: Protein adsorption on different dextran-coated nanoparticles and corresponding status of the activation of protein $\mathrm{C} 3$ of the complement system. The circles at the bottom represent the balance between proteins of high molecular weight (>100 kDa) (dark grey and black) and low molecular weight ( $<100 \mathrm{kDa}$ ) (light grey) that were found adsorbed at the nanoparticle surface after incubation in plasma. For proteins of high molecular weight, a difference was made between fibrinogen (in black) and immunoglobulins (in dark grey).

Adsorption of these proteins on the surface of nanoparticles is in contradiction with their capacity to prevent the activation of the complement system. It is also in contradiction with the structure of a dense brush of polysaccharide chains forming the nanoparticle corona that should exclude large 
proteins from adsorption on nanoparticles. Although these results disagreed with results obtained from previous studies carried out on almost neutral nanoparticles designed with a corona composed of PEG and dextran, they agreed with those reported by the group of Ballauff investigating protein adsorption on nanoparticles coated with brushes of polyelectrolytes [Wittemann et al. 2003, Welsch et al. 2013]. These authors suggested that adsorption of proteins resulted from ionic interactions taking place between the negative charges of the polyelectrolyte grafted on the nanoparticle surface and patches of positive charged found on the proteins. It is believed that the proteins can then adsorb as a multivalent counter-ion after displacement of the monovalent counter-ion found along the polyelectrolyte chains of the brush formed at the nanoparticle surface. This effect can take place event at the most external sites of the nanoparticle corona as illustrated on figures $4 \mathrm{~A}$ and $4 \mathrm{~B}$. The remarkable property of dextran sulphate to hinder activation of the complement system despite the adsorption of immunoglobulin and fibrinogen need to be elucidated. However, it can be assumed that the mechanism behind this effect is different from that depicted with the dextran-coated nanoparticles and based on a steric exclusion effect.

At this stage, we can identify that polysaccharide-coated nanoparticles can prevent activation of the complement system and control adsorption of proteins by at least two mechanisms that were summarized in Table 3. More work is now needed to understand how proteins are interacting with those nanoparticles and what the role of the polysaccharide corona in this interaction is. Nevertheless, the highly charged nanoparticles appeared as potential drug carriers that are able to bypass recognition mechanisms of the immune system followed by the activation of the complement cascade. Their capacity to adsorb high molecular weight proteins without triggering the activation of the complement system is a new property. It can reasonably be assumed that they will show a different biodistribution compared to that of the nanoparticles having a corona that selects small molecular weight proteins thanks to a steric effect. We are still at the very beginning of the understanding on how polysaccharides can be used to tune nanoparticle properties to modulate protein adsorption in a perfectly controlled manner. Nevertheless, it already seems that polysaccharides occurring in various natures can offer much wider possibilities to finely tune interactions between proteins and nanoparticles and in turn to give a wider range of possibilities to control the in vivo fate of drug carriers then PEG. Another very exiting perspective can emerged from the elucidation of the glyco-code that may provide keys to design nanoparticles having very defined interactions with proteins and in turn to obtain better controlled physiological responses and finally in vivo distribution. 
Author manuscript published in: «Biointeractions of Nanomaterials". Vijaykumar B. Sutariya and Yashwant Pathak, Editors. CRC Press, Taylor and Francis. Bocca Raton, FL. July 2014. Chap 18, pp. 365-382

Table 3: Summary on mechanisms controlling activation of the complement system and adsorption of proteins by polysaccharide-coated nanoparticles and major type of proteins adsorbed on corresponding nanoparticles.

\begin{tabular}{|c|c|c|c|}
\hline $\begin{array}{l}\text { Composition of the } \\
\text { nanoparticle corona = } \\
\text { brush } \\
\text { polysaccharide }\end{array}$ & Proposed mechanism behind the control of the adsorption of proteins & $\begin{array}{l}\text { Mechanism behind the } \\
\text { control of the } \\
\text { activation of the } \\
\text { complement system }\end{array}$ & Type of adsorbed proteins \\
\hline Dextran $>60 \mathrm{kDa}$ & $\begin{array}{l}\text { Adsorption on the hydrophobic core surface of the nanoparticles after } \\
\text { diffusion through the polysaccharide corona. Selection of proteins that } \\
\text { can adsorbed arises by the characteristics of the nanoparticle corona } \\
\text { which function as a molecular sieve and by the size and shape of } \\
\text { proteins which should fit with that of the hydrophobic spaces available } \\
\text { on the nanoparticle core surface. }\end{array}$ & Steric exclusion & $\begin{array}{l}\text { Majority of low molecular } \\
\text { weight protein } \\
\text { (apolipoprotein A1 (Mw 28.08 } \\
\text { kDa) and C2 (Mw } 11.3 \mathrm{kDa}) \text { ) }\end{array}$ \\
\hline Heparin & $\begin{array}{l}\text { Adsorption of proteins as a multivalent counterion by interactions of the } \\
\text { charges of the polysaccharides composing the nanoparticle corona. }\end{array}$ & $\begin{array}{l}\text { Known activity against } \\
\text { complement } \\
\text { activation. } \\
\text { Interference with } \\
\text { factor H of the } \\
\text { complement cascade }\end{array}$ & $\begin{array}{l}\text { Majority of high molecular } \\
\text { weight } \\
\text { Immunoglobulin, fibrinogen }\end{array}$ \\
\hline Dextran sulphate & $\begin{array}{l}\text { Adsorption of proteins as a multivalent counterion by interactions of the } \\
\text { charges of the polysaccharides composing the nanoparticle corona. }\end{array}$ & To elucidate & $\begin{array}{l}\text { Majority of high molecular } \\
\text { weight } \\
\text { Immunoglobulin (Mw } 150 \\
\text { kDa), fibrinogen (Mw } 340 \mathrm{kDa} \text { ) }\end{array}$ \\
\hline Chitosan & To elucidate & To elucidate & Unknown \\
\hline
\end{tabular}




\section{Conclusion}

Nanoparticles with a wide range of surface properties can be designed choosing polysaccharides to create a hydrophilic corona on their surface. This strategy of modification of surface properties influences greatly the type and amounts of proteins that adsorb on the nanoparticle surface and the capacity of the nanoparticles to trigger activation of the complement system. Interestingly, control of the interactions of proteins with the nanoparticle surface can be achieved according to different mechanisms by choosing the nature of the polysaccharide composing the nanoparticle corona and designing the structure of the nanoparticle corona. More investments are needed on systematic and fundamental works to explore the full potential of the approach and to better understand how we can use polysaccharide to finely tune interactions of proteins with the nanoparticles. This will constitute a first step to the understanding of the physiological response and in turn of the biodistribution after intravenous administration. The wide range of surface characteristics that can be generated in a controlled manner may also be an opportunity for having access of model nanoparticles that could be used to investigate sites of accumulation of nanomaterials depending on the profile of adsorbed proteins and interactions with the immune system. This would deserve a rationalization of approaches developed to design more efficient drug carriers and the understanding of potential toxicological profiles of nanomaterials from their interactions with proteins.

\section{References}

Alexis, F., Pridgen, E., Molnar, L.K. and Farokhzad, O.C. 2008. Factors affecting the clearance and biodistribution of polymeric nanoparticles. Mol. Pharm. 5:505-15.

Algar, W.R., Prasuhn, D.E., Stewart, M.H., Jennings, T.L., Blanco-Canosa, J.B. et al. 2011. The controlled display of biomolecules on nanoparticles: a challenge suited to bioorthogonal chemistry. Bioconjug. Chem. 22:825-58.

Anderson, N.L., Polanski, M., Pieper, R., Gatlin, T., Tirumalai, R.S., Conrads, T.P. et al. 2004. The human plasma proteome: a nonredundant list developed by combination of four separate sources. Mol. Cell Proteomics. 3:311-26.

Andrieux, K., and Couvreur, P. 2009. Polyalkylcyanoacrylate nanoparticles for delivery of drugs across the blood-brain barrier. Wiley Interdiscip. Rev. Nanomed. Nanobiotechnol. 1:463-74.

Ballauff, M. 2007. Spherical polyelectrolyte brushes. Prog. Polym. Sci. 32:1135-51.

Banerjee, I., Pangule, R.C., Kane, R.S. 2011. Antifouling coatings: recent developments in the design of surfaces that prevent fouling by proteins, bacteria, and marine organisms. Adv. Mater. 23:690-718.

Bangham, A. D., Standish, M. M. and Watkins, J. C. 1965. Diffusion of univalent ions across the lamellae of swollen phospholipids. J. Mol. Biol. 13:238-52.

Bakht, M.K., Sadeghi, M., Pourbaghi-Masouleh, M. and Tenreiro, C. 2012. Scope of nanotechnologybased radiation therapy and thermotherapy methods in cancer treatment. Curr. Cancer Drug Targets. 12:998-1015.

Ballauff, M. and Borisov, O.V. 2006. Polyelectrolyte brushes. Curr. Opin. Colloid Interf. Sci. 11 :316-23.

Bertholon, I., Vauthier, C., Labarre, D. 2006a. Complement Activation by Core-Shell Poly(isobutylcyanoacrylate)-Polysaccharide Nanoparticles: Influences of Surface Morphology, Length, and Type of Polysaccharide. Pharm. Res. 23:1313-1323. 
Bertholon, I., Lesieur, S., Labarre, D., Besnard, M. and Vauthier C. 2006b. Characterization of dextranpoly(isobutylcyanoacrylate) copolymers obtained by redox radical and anionic emulsion polymerization. Macromolecules. 39:3559-67.

Bertholon, I., Hommel H., Labarre D. and Vauthier, C. 2006c. Properties of Polysaccharides Grafted on Nanoparticles Investigated by EPR. Langmuir. 22:5485-90.

Bravo-Osuna, I., Vauthier, C., Farabollini, A., Palmieri, G.F. and Ponchel, G. 2007) Mucoadhesion mechanism of chitosan and thiolated chitosan-poly(isobutyl cyanoacrylate) core-shell nanoparticles. Biomaterials. 28:2233-43.

Chauvierre, C., Labarre, D., Couvreur, P. and Vauthier C. 2003. Novel polysaccharide-decorated poly(isobutyl cyanoacrylate) nanoparticles. Pharm. Res. 20:1786-93.

Chauvierre, C., Vauthier, C., Labarre, D. and Hommel, H. 2004. Evaluation of the surface properties of dextran coated poly(isobutylcyanocrylate) nanoparticles by Spin-labelling coupled with electron resonance spectroscopy. Coll. Polym. Sci. 282:1016-25.

Couvreur, P. and Vauthier, C. 2006. Nanotechnology: intelligent design to treat complex disease. Pharm. Res. 23:1417-50.

Daniel J.C. 2003. A long history with many future challenges to meet in the future - Free-radical emulsion polymerization and aqueous polymer dispersions. In: Colloidal polymers, synthesis and characterisation, Surfactant Science Series. Ed. A. Elaissari, 115:1-22. New York: Marcel Dekker.

Dobrovolskaia, M.A., Aggarwal, P., Hall, J.B. and McNeil, S.E. 2008. Preclinical studies to understand nanoparticle interaction with the immune system and its potential effects on nanoparticle biodistribution. Mol. Pharm. 5:487-95.

Douglas, S.J., Illum, L., Davis, S.S. and Kreuter, J. 1984. Particle size and size distribution of poly(butyl 2 cyanoacrylate) nanoparticles. Influence of physicochemical factors. J. Coll. Interface Sci. 101: 149158.

Etheridge, M.L., Campbell, S.A., Erdman, A.G., Haynes. C,L,, Wolf. S,M. and McCullough. J. 2013. The big picture on nanomedicine: the state of investigational and approved nanomedicine products. Nanomedicine:NBM. 9:1-14.

Estephan, Z.G., Jaber, J.A. and Schlenoff, J.B. 2010, Zwitterion-stabilized silica nanoparticles: toward nonstick nano. Langmuir. 26:16884-9.

Farokhazad, O.C., Langer, R. 2009. Impact of nanotechnology on drug delivery. ACS Nano. 1:16-20.

Gref, R., Lück, M., Quellec, P., Marchand, M., Dellacherie, E., Harnisch, S. et al. 2000. 'Stealth' coronacore nanoparticles surface modified by polyethylene glycol (PEG): influences of the corona (PEG chain length and surface density) and of the core composition on phagocytic uptake and plasma protein adsorption. Colloids Surf B Biointerfaces. 18:301-13.

Gref, R., Minamitake, Y., Peracchia, M.T., Domb, A., Trubetskoy, V., Torchilin, V. et al. 1997. Poly(ethylene glycol)-coated nanospheres: potential carriers for intravenous drug administration. Pharm. Biotechnol. 10:167-98.

Gref, R., Minamitake, Y., Peracchia, M.T., Trubetskoy, V., Torchilin, V., Langer, R. 1994. Biodegradable long-circulating polymeric nanospheres. Science 263:1600-3

Gregoriadis, G. 1976. The carrier potential of liposomes in biology and medicine. N. Eng. J. Med. 295:704-10.

Gregoriadis, G., Wills, E.J., Swain, C.P. and Tavill, A.S. 1974. Drug-carrier potential of liposomes in cancer chemotherapy. Lancet. 1:1313-6. 
Hirsh, S.L., McKenzie, D.R., Nosworthy, N.J., Denman, J.A., Sezerman, O.U. and Bilek, M.M.M. 2013. The Vroman effect: Competitive protein exchange with dynamic multilayer protein aggregates. Coll. \& Surf. B: Biointerfaces 103:395-404

Jeon, S.I. and Andrade, J.D. 1991. Protein-surface interactions in the presence of polyethylene oxide: II. Effect of protein size. J. Coll. Interf. Sci. 142: 159-166

Jeon, S.I., Lee, J.H., Andrade, J.D. and De Gennes P.G. 1991. Protein-surface interactions in the presence of polyethylene oxide: I. Simplified theory. J. Coll. Interf. Sci. 142: 149-158.

Jiskoot, W., Van Schie, R.M.F., Carstens, M.G., Schellekens, H. 2009. Immunological risk of injectable drug delivery systems. Pharm. Res. 26: 1303-14.

Juliano, R.L. 1976. The role of drug delivery systems in cancer chemotherapy. Prog. Clin. Biol. Res. 9:21-32.

Julien, N. and Vauthier, C. 2011. Poly(alkylcyanoacrylate) nanosystems. In "Intracellular Delivery Fundamental Biomedical Technologies" ed. A. Prokov, 225-51. New York: Springer.

Kreuter, J. 2007. Nanoparticles - A historical perspective. Int. J. Pharm. 331:1-10.

Kreuter, J. and Speiser, P. P. 1976. New adjuvants on a polymethylmethacrylate base. Infect. Immun. 13, 204-210.

Labarre, D., Vauthier, C., Chauvierre, C., Petri, B., Muller, R.H. and Chehimi, M.M. 2005. Interactions of blood proteins with poly (isobutylcyanoacrylate) nanoparticles decorated with a polysaccharidic brush. Biomaterials. 26:5075-84.

Lehner, R., Wang, X., Marsch, S., Hunziker, P. 2013. Intelligent nanomaterials for medicine: Carrier platforms and targeting strategies in the context of clinical application. Nanomedicine:NBM doi: 10.1016/j.nano.2013.01.012.

Lemarchand, C., Gref, R., Couvreur, P. 2004. Polysaccharide-decorated nanoparticles. Eur. J. Pharm. Biopharm. 58:327-41.

Li, S.D., Huang, L. 2008. Pharmacokinetics and biodistribution of nanoparticles. Mol. Pharm. 5:496504.

Lira, M.C.B., Santos-Magalhães, N.S., Nicolas, V., Marsaud, V., Silva, M.P., Ponchel, G. et al. 2011 Cytotoxicity and cellular uptake of newly synthesized fucoidan-coated nanoparticles. Eur. J. Pharm. Biopharm. 79:162-170

Liu, F., Laurent, S., Fattahi, H., Vander Elst, L. and Muller, R.N. 2011. Superparamagnetic nanosystems based on iron oxide nanoparticles for biomedical imaging. Nanomedicine (Lond). 6:519-28.

Lynch, I., Cedervall, T., Lundqvist, M., Cabaleiro-Lago, C., Linse, S. et al. 2007. The nanoparticleprotein complex as a biological entity; a complex fluids and surface science challenge for the 21st century. Adv. Colloid Interface Sci. 134-135:167-74

Moyano, D.F. and Rotello, V.M. 2011. Nano meets biology: Structure and function at the nanoparticle interface. Langmuir. 27:10376-85

Mura, S., Couvreur, P. 2012. Nanotheranostics for personalized medicine. Adv. Drug Deliv. Rev. 64:1394-416.

Nicolas, J., Couvreur, P. 2009. Synthesis of poly(alkyl cyanoacrylate)-based colloidal nanomedicines. Wiley Interdiscip. Rev. Nanomed. Nanobiotechnol. 1:111-27

Nilsson, B., Ekdahl, K.N., Mollnes, T.E., Lambris, J.D. 2007. The role of complement in biomaterialinduced inflammation. Mol. Immunol. 44:82-94. 
Norde, W. 2008. My voyage of discovery to proteins in flatland...and beyond. Coll. Surf. B. Biointerface. 61:1-9.

Owens, D.E. and Peppas, N.A. 2006. Opsonization, biodistribution and pharmacokinetics of polymeric nanoparticles. Int. J. Pharm. 307:93-102.

Papahadjopoulos, D., Allen, T.M., Gabizon, A., Mayhew, E., Matthay, K., Huang, S.K. et al. 1991. Sterically stabilized liposomes: improvements in pharmacokinetics and antitumor therapeutic efficacy. Proc. Natl. Acad. Sci. U.S.A. 88:11460-4.

Passirani, C., Ferrarini, L,. Barratt, G., Devissaguet, J.P. and Labarre, D. 1999. Preparation and characterization of nanoparticles bearing heparin or dextran covalently-linked to poly(methyl methacrylate). J. Biomater. Sci. Polym. Ed. 10:47-62.

Peracchia, M.T., Fattal, E., Desmaële, D., Besnard, M., Noël, J.P., Gomis, J.M. et al. 1999. Stealth PEGylated polycyanoacrylate nanoparticles for intravenous administration and splenic targeting. J. Control. Release. 60:121-8.

Sahli, H., Tapon-Bretaudière, J., Fischer, A.M., Sternberg, C., Spenlehauer, G., Verrecchia, T. et al. 1997. Interactions of poly (lactic acid) and poly(lactic acid-co-ethylene oxide) nanoparticles with the plasma factors of the coagulation system. Biomaterials. 18:281-8.

Szebeni, J., Muggia, F.;, Gabizon, A. and Barenholz, Y. 2011. Activation of complement by therapeutic liposomes and other lipid excipient-based therapeutic products: prediction and prevention. Adv. Drug Deliv. Rev. 63:1020-30.

Vauthier, C., Labarre, D., Ponchel, G. 2007b. Design aspects on poly(alkylcyanoacrylate) nanoparticles for targeted drug delivery. J. Drug Targeting. 15: 641-63.

Vauthier, C., Lindner, P. and Cabane, B., 2009. Configuration of Bovine Serum Albumin adsorbed on polymer particles with grafted dextran corona. Coll. \& Surf. B: Biointerfaces. 69:207-15.

Vauthier, C., Persson, B., Lindner, P. and Cabane, B. 2011. Protein adsorption and complement activation for di-block copolymer nanoparticles. Biomaterials. 32:1646-56

Vonarbourg, A., Passirani, C., Saulnier, P. and Benoit, J.P. 2006. Parameters influencing the stealthiness of colloidal drug delivery systems. Biomaterials. 27:4356-73.

Walczyk, D., Baldelli Bombelli, F., Monopoli, M.P., Lynch, I., Dawson, K.A. 2010. What the cell "sees" in bionanoscience. J. Am. Chem. Soc. 132:5761-68.

Walkey, C.D. and Chan W.C.W. 2012. Understanding and controlling the interaction of nanomaterials with proteins in a physiological environment. Chem. Soc. Chem. 41, 2780-99.

Walkey, C.D., Olsen, J.B., Guo, H., Emili, A. and Chan, W.C. 2012. Nanoparticle size and surface chemistry determine serum protein adsorption and macrophage uptake. J. Am. Chem. Soc. 134:213947.

Wang, R., Billone, P.S. and Mullet, W.M. 2013. Nanomedicine in Action: An Overview of Cancer Nanomedicine on the Market and in Clinical Trials. J. Nanomed. DOI : 10.1155/2013/629681

Welsch, N., Lu, Y., Dzubiella, J., Ballauff, M. 2013. Adsorption of proteins to dunctional polymeric nanoparticles. Polymer. 54:2835-49.

Wittemann, A., Haupt, B., Ballauff, M. 2003. Adsorption of proteins on spherical polyelectrolyte brushes in aqueous solution. Phys. Chem. Chem. Phys. 5:1671-7.

Zandanel, C. and Vauthier C. 2012. Poly(isobutylcyanoacrylate) nanoparticles decorated with chitosan: Effect of conformation of chitosan chains at the surface on complement activation properties. J. Coll. Sci. Biotechnol. 1: 68-81. 